\title{
Sosialisasi Penggunaan Online Shop Berbasis Website di UMKM Cimanggis
}

\author{
Rofiq Noorman Haryadi ${ }^{1}$, Anda Rojali ${ }^{2}$, Khumidin ${ }^{3}$, M. Fauzan ${ }^{4}$ \\ ${ }^{1}$ STEBIS Bina Mandiri, Bogor, Indonesia \\ 2,3,4 STEBIS Bina Mandiri, Bogor, Indonesia \\ rofiq.stebis@gmail.com
}

\begin{abstract}
Abstrak: Kegiatan ini dilaksanakan untuk meningkatkan tingkat pemahaman dan untuk memberikan ilmu pengetahuan kepada masyarakat yang ada di UCC (UMKM Center Cimanggis) Cimanggis, Depok, Jawa Barat. Tujuan pengabdian kepada masyarakat ini adalah untuk menambah pengetahuan mengenai jual beli online shop berbasis website yang telah disediakan sebelumnya. Diharapkan dari hasil sosialisasi ini dapat memberikan pemahaman baru mengenai jual beli online, pengembangan jual beli online, dan pemahaman tentang jual beli online kepada masyarakat atau anggota UCC. Kegiatan ini dilaksanakan dengan menggunakan metode ceramah dan diskusi. Metode ceramah digunakan dalam proses penyampaian materi pelatihan/sosialiasi. Sedangkan metode diskusi digunakan agar anggota UCC bisa berdiskusi tentang bisnis online berdasarkan online shop berbasis website. Target luaran yang diharapkan dari kegiatan ini adalah 1) Anggota UCC Cimanggis mampu mengetahui bagaimana proses jual beli secara online; 2) Anggota UCC Cimanggis mendapatkan infromasi tentang cara menggunakan website dalam jual beli online. 3) Masyarakat nantinya mampu mengembangkan bisnis jual beli online berbasis website.
\end{abstract}

Kata Kunci: Online shop, Jual Beli, UMKM

Abstract: This activity was carried out to increase the level of understanding and to provide knowledge to the community at UCC (Cimanggis UMKM Center) Cimanggis, Depok, West Java. The purpose of this community service is to increase knowledge about buying and selling online shop based websites that have been provided previously. It is hoped that the results of this socialization can provide a new understanding of online buying and selling, the development of online buying and selling, and an understanding of online buying and selling to the public or UCC members. This activity is carried out using lecture and discussion methods. The lecture method is used in the process of delivering training/socialization materials. While the discussion method is used so that UCC members can discuss online business based on a website-based online shop. The expected output targets of this activity are 1) UCC Cimanggis members are able to know how the process of buying and selling online is; 2) UCC Cimanggis members get information on how to use the website in buying and selling online. 3) The community will be able to develop a website-based online buying and selling business

Keywords: Online shop, buy and sell, UMKM

\section{Pendahuluan}

Penjualan online adalah suatu aktifitas jual beli yang dilakukan secara online, dalam hal ini pembeli dan penjual tidak melakukan transaksi langsung secara tatap muka. Dengan demikian transaksi yang dilakukan menggunakan sebuah media atau alat sebagai penghubung antara penjual yang menawarkan produknya kepada calon pembeli dan pembeli mendapatkan penawaran produk secara online. Tentu media yang digunakan dapat berupa website maupun aplikasi yang di akses melalui perangkat elektronik yang terhubung dengan internet.

Masyarakat Cimanggis khususnya anggota UMKM yang tergabung di UCC (UMKM Center Cimanggis) masih banyak yang belum bisa memanfaatkan media online berbasis website sebagai fasilitas dalam penjualan atau promosi produk kepada konsumen, dikarenakan masih banyak anggota UMKM Cimanggis yang memasarkan atau mempromosikan hasil produknya melalui whatsapp status. Keterbatasan jangkauan atau target penjualan yang dilakukan melalui 
whatsapp tidaklah luas, maka dibutuhkan sebuah media yang membantu anggota UCC dalam memasarkan produknya kepada masyarakat umum.

Pemanfaatan media online berbasis website ini tergolong pada E-Commerce dimana menurut Sri Haryanti, Tri Irianto. (2011) "E-Commerce adalah Bisnis yang dilakukan secara elektonik yang melibatkan aktifitas-aktifitas bisnis berupa business to business atau business to consumen melalui teknologi internet." Sedangkan E-Business merupakan transaksi yang digunakan untuk proses menjual atau pembelian beberapa produk menggunakan teknologi ICT (Information and Communication Technology). Sedangkan jual beli adalah bentuk dasar dari kegiatan ekonomi manusia dan merupakan aktifitas yang sangat dianjurkan dalam ajaran agama Islam (Tira, 2017).

Dengan adanya UMKM sebagai penggerak roda perekonomian nasional terbukti sangat berkontribusi dan perannya dalam menyerap tenaga kerja lebih banyak dibanding bisnis lainnya, dengan demikian bahwa UMKM dapat menekan jumlah angka pengangguran dan kemiskinan. Permasalahan yang umum dihadapi pelaku UMKM seperti keterbatasan permodalan, SDM yang kurang kompeten di bidangnya dan pemanfaatan teknologi perlu mendapat dukungan dari berbagai pihak dalam bentuk penguatan.

Adapun tujuan dari sosialisasi penggunaan online shop berbasis website ini adalah 1 . Memberikan pengetahuan kepada para pelaku usaha yang tergabung di UMKM Cimanggis, 2. Mengajak para pelaku usaha untuk memanfaatkan teknologi dalam berbisnis jual beli.

\section{Metode}

Metode yang dilakukan oleh penulis berdasarkan beberapa langkah antara lain:

1. Menganalisis sistem penjualan online yang sudah dilakukan oleh anggota UCC sebagai penjual kepada pembeli di lingkup masyarakat Cimanggis, Depok, Jawa Barat. Berdasarkan analisis ini akan ditemukan solusi yang dapat dilakukan oleh anggota UCC sebagai penjual.

2. Merancang sebuah program yang dapat diadopsi oleh anggota UCC berdasarkan permasalahan yang terjadi di lingkungan anggota UCC dalam proses jual beli. Dengan demikian penulis menemukan sebuah media yang tepat untuk dapat digunakan oleh anggota UCC yakni media jual beli berbasis website.

3. Mendesain program jual beli online berbasis website dengan menggunakan sistem kerja PHP yang terintegrasi melalui sebuah hosting dengan sebuah domain untuk dapat di akses oleh masyarakat umum di mana masyarakat mengetik alamat website yang sudah direncanakan.

4. Penulis kemudian menguji program ini terlebih dahulu untuk memastikan tingkat kesalahan penggunaan seminimal mungkin bersama beberapa anggota UCC Cimanggis, Depok, Jawa Barat dan agar di kemudian hari dapat di kaji ulang sebagai bagian dari perbaikan sistem.

5. Program yang telah di desain merupakan program open-source dengan single-admin. Dimana program jual beli online berbasis website ini masih dikendalikan oleh seorang operator/admin dalam transaksi jual beli dari penjual kepada pembeli maupun sebaliknya. Adapun operator yang melakukan pengawasan transaksi jual beli online ini adalah salah 
satu anggota pengurus UCC Cimanggis, Depok, Jawa Barat.

6. Penulis melakukan pemeliharaan dari penerapan program yang telah dijalankan agar saat terjadi kesalahan sistem akan dapat langsung diperbaiki berdasarkan laporan dari operator yang ditunjuk sebagai admin.

\section{Hasil dan Pembahasan}

\section{A. Tampilan Website}

Tampilan Website jual beli online berbasis website ini dapat diperjelas dengan beberapa tampilan yakni antara lain;

1. Tampilan halaman utama pengunjung

Pada tampilan laman utama pengunjung yang menyajikan informasi lengkap mengenai semua kategori yang tersedia di laman website seperti kategori kuliner, kesehatan, gadget dan fashion yang dilengkapi dengan iklan pada sisi atas berupa slide yang berjalan otomatis dengan waktu pergantian iklan telah ditentukan oleh sistem. Laman website ini dapat diakses dengan mudah pada link https://swacim.com seperti yang ditampilkan pada Gambar 1 dibawah ini.

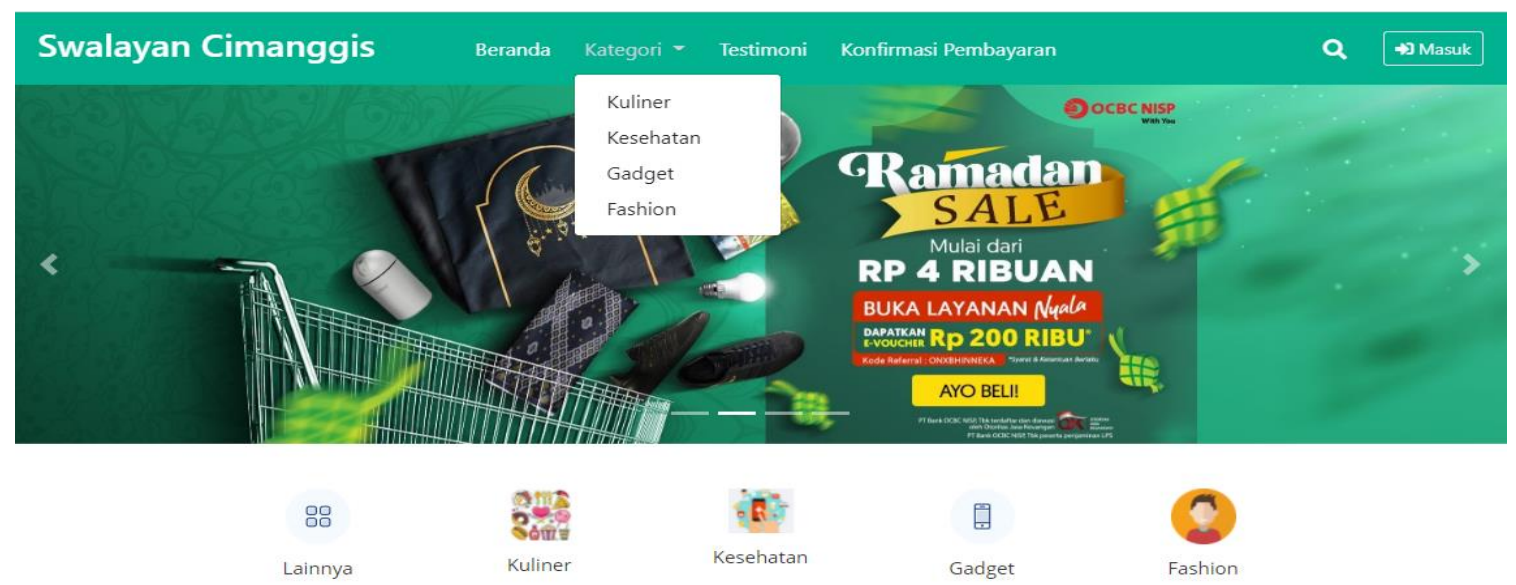

Gambar 1. Tampilan Awal Program

2. Tampilan laman Login

Pada laman login ini menampilkan beberapa field untuk mengisi username dan password pengguna baik pengguna baru maupun yang sudah mendaftar sebelumnya. Pada laman ini pun pengguna baru bisa melakukan pendaftaran dengan cara klik Daftar pada tukisan yang telah disediakan seperti pada gambar 2 berikut ini;

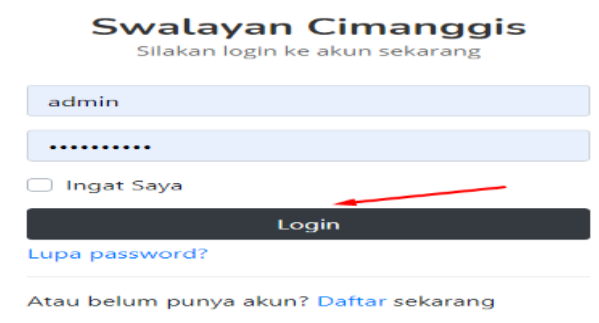

Gambar 2. Laman Menu Login 
3. Tampilan laman daftar

Pada laman ini disediakan beberapa field untuk mendaftarkan diri agar memudahkan proses transaksi penjual dan pembeli. Adapun sebagai syarat mendaftarkan diri adalah seperti memasukkan nama lengkap, alamat surel aktif, password yang akan digunakan dikemudian hari dan mengonfirmasikan kembali password yang telah diisi untuk memastikan tidak terjadi kesalahan dalam proses login. Berikut laman daftar yang ditampilkan pada gambar 3;

Swalayan Cimanggis

Daftar akun baru sekarang

Nama Lengkap
Alamat Email
Password
Konfirmasi Password
Saya telah membaca dan menyetujui Syarat dan Ketentuan
Serta Kebijakan Privasi Swalayan Cimanggis
Daftar

Atau sudah punya akun? Login sekarang

Gambar 3. Tampilan laman Daftar

4. Tampilan laman order

Pada laman order, pembeli dapat melihat dan melanjutkan proses pembelian dari apa yang telah dipesan sebelumnya untuk dilakukan proses pembayaran. Proses pembayaran pembeli akan masuk ke menu laman admin/operator yang nantinya akan diteruskan kepada penjual untuk mengkonfirmasi ketersediaan produk. Seperti pada gambar 4 berikut;

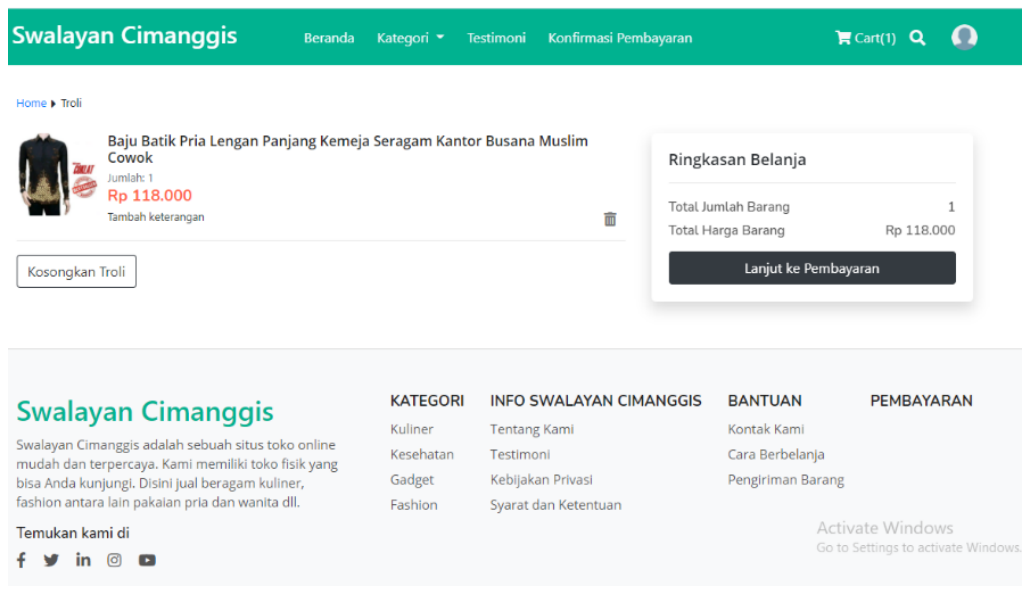

Gambar 4. Tampilan laman Order 
5. Tampilan laman jasa pengirim/kurir

Yang disajikan pada laman jasa kurir ini adalah laman tempat pembeli dapat memilih jasa kurir/pengiriman yang telah disediakan seperti jasa pengiriman TIKI, JNE, POS dan menyediakan pilihan $C O D$ untuk jarak yang telah ditentukan sebelumnya.

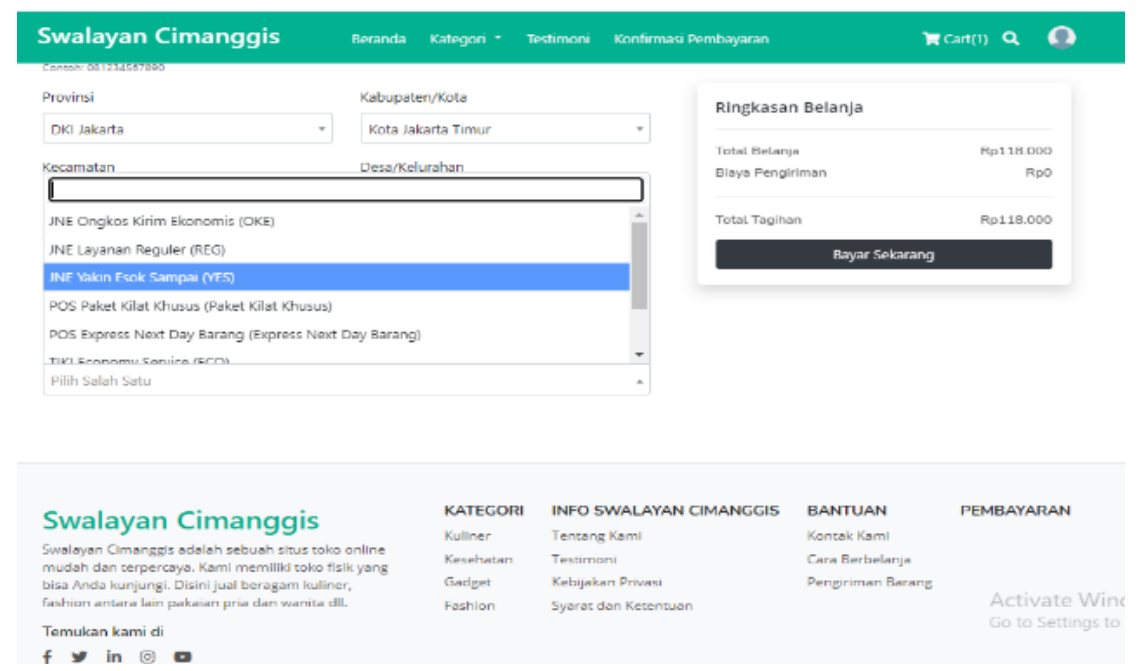

Gambar 5. Tampilan Jasa Pengiriman/Kurir

\section{B. Pengujian Media Online Shop berbasis Website}

Setelah proses pembuatan website yang nantinya akan digunakan sebagai media jual beli yang dilakukan oleh para anggota UCC dengan masyarakat. Maka, perlu diadakan pengujian kelayakan agar dapat dipergunakan dengan baik oleh penjual dan pembeli. Pengujian ini dilakukan dengan mencoba beberapa produk yang dihasilkan oleh pelaku usaha dari UMKM Cimanggis yang kemudian di unggah oleh admin/operator ke laman dashboard agar dapat tampil di laman konsumen. Setelah admin/operator selesai mengunggah data produk seperti foto produk, deskripsi produk, harga produk, alamat penjual dan ketersediaan stok produk, laman utama sudah menampilkan produk yang hendak di jual belikan.

Kemudian penulis mencoba mengakses laman Swalayan Cimanggis ini dan memesan 1 produk yang telah tampil pada laman umum. Penulis mencoba untuk memesan 1 produk dari Swalayan Cimanggis untuk di beli, setelah mengklik produk dan membaca deskripsi yang ditawarkan, penulis memasukkan produk ke keranjang belanja untuk dilakukan transaksi selanjutnya. Pada tampilan ini terdapat beberapa pilihan pengiriman yang dapat di pilih, selanjutnya penulis kembali mengakses laman dashboard admin untuk mengecek apakah pesanan yang telah dilakukan muncul pada laman pemesanan. Setelah muncul pemberitahuan akan adanya pemesanan, admin/operator mengirimkan deskripsi pemesanan kepada penjual melalui pesan singkat menggunakan aplikasi whatsapp yang kemudian penjual mempersiapkan produk yang dipesan untuk diirimkan kepada alamat yang telah terekam saat mendaftarkan diri pada website online shop Swalayan Cimanggis ini. 


\section{Simpulan}

Dari hasil pengabdian yang dilakukan di UCC (UMKM Center Cimanggis) ini menghasilkan kesimpulan yakni sebagai berikut;

1. Pelaksanaan dalam memberikan sosialisasi penggunaan online shop berbasis website pada para pelaku usaha yang tergabung di UCC Cimanggis, Depok, Jawa Barat terlaksana dengan baik sesuai jadwal yang telah ditentukan sebelumnya.

2. Pemberian materi sosialisasi penggunaan online shop berbasis website di UMKM Cimanggis ini mendapatkan respon positif oleh para pelaku usaha yang tergabung di UCC (UMKM CenterCimanggis) yang ditandai dengan antusiasme pelaku usaha dalam mengelola usaha yang sudah digelutinya.

3. Sistem pengelolaan online shop berbasis website dapat berjalan sesuai dengan kaidah sistem yang telah dirancang sebelumnya, ditandai dengan pengujian keseluruhan aspek pendukung perjalanan sistem ini baik dari laman admin/operator sebagai pelaku update data pada sistem untuk konsumen. Juga, laman konsumen yang dapat dijalankan dengan mudah dan responsif dalam merekam jejak pemesanan hingga pelaporan barang yang sudah diterima oleh konsumen.

4. Pada sistem ini menerapkan model verifikasi yang sangat aman untuk menjaga kepercayaan konsumen terhadap penjual juga kepada UMKM Cimanggis yang ditandai dengan terverifikasinya anggota UMKM Cimanggis. Dengan kata lain, selain anggota UCC tidak akan dapat melakukan penjualan/penawaran produknya di website online shop Swalayan Cimanggis. Begitupun dengan proses pembayaran yang dilakukan oleh konsumen tidak langsung ke penjual, namun masuk ke rekening yang telah disediakan oleh UCC (UMKM Center Cimanggis).

5. Pengujian yang dilakukan telah teruji dengan baik untuk setiap laman yang dibutuhkan seperti laman pendaftaran, laman update data produk, laman admin, laman konsumen saat memesan dan laman pendeteksian status proses pemesanan. Sehingga proses transaksi yang dilakukan melalui online shop berbasis website yang diberi nama Swalayan Cimanggis ini dapat dipercaya dan mampu membantu para pelaku UMKM yang tergabung pada UCC untuk memasarkan produknya ke masayrakat yang lebih luas.

\section{Saran}

Untuk menyempurnakan website ini, adanya saran yang di dapat oleh penulis antara lain;

1. Perlu adanya pengembangan pada sistem yang telah berjalan dimana penjual dapat mengeksekusi produknya untuk dapat diunggah pada sistem dengan mandiri namun tetap dalam pengawasan atau persetujuan admin/operator sebagai super admin dalam pengelolaan jual beli di website online shop ini,

2. Adanya pengembangan sistem yang tidak hanya berbasis website namun juga sebuah aplikasi yang dapat di unduh melalui Smartphone/Playstore. Dengan kata lain, 
pengembangan berbasis android untuk memudahkan segala hal dikarenakan sekarang sedang marak aplikasi berbasis android.

\section{Ucapan Terima Kasih}

Dalam suksesnya pelaksanaan proses pengabdian yang dilakukan dengan judul "Sosialisasi Penggunaan Online Shop berbasis Website di UMKM Cimanggis" ini. Penulis mengucapkan terima kasih kepada Camat Cimanggis beserta jajarannya, Ketua UCC (UMKM Center Cimanggis) beserta jajarannya, kepada para pelaku usaha yang sudah hadir dalam pelaksanaan kegiatan pengabdian ini, kepada Ketua Sekolah Tinggi Ekonomi Bisnis Syariah Bina Mandiri beserta jajarannya yang telah mengizinkan kegiatan pengabdian ini dan kepada LPPM Sekolah Tinggi Ekonomi Bisnis Syariah Bina Mandiri yang telah memfasilitasi kegiatan pengabdian.

\section{Referensi}

Sri Haryanti, Tri Irianto. (2011). Rancang Bangun Sistem Informasi E-Commerce Untuk Usaha Fashion Studi Kasus Omah. Universitas Surakarta. Surakarta.

Salim, Munir. (2017). Jual Beli Secara Online Menurut Pandangan Hukum Islam. Jurnal Al Daulah, Vol. 6 No. 2.

Fitria, T. N. (2017). Bisnis jual beli online (online shop) dalam Hukum Islam dan Hukum Negara. Jurnal Ilmiah Ekonomi Islam, 3(01), 52-62.

Gunartin (2017). Penguatan UMKM Sebagai Pilar Membangun Ekonomi Bangsa. Jurnal Eduka, Vol. 2 No. 2.

Endah, Alberthiene. (2015). Chloe: Sukses Berbisnis Online Shop. Jakarta: Gramedia Pustaka Utama. 